\begin{tabular}{ll}
\hline INDEX TO ADVERTISERS & \\
\hline Advanced Microscopy Techniques & A5 \\
Brüker AXS & A13 \\
Cambridge University Press & 116 \\
DiATOME & Cover 3 \\
EDAX & A12 \\
Electron Microscopy Sciences, EMS & A9, 113, 115 \\
Gatan & A3 \\
JEOL & Cover 4 \\
Leica Microsystems & Cover 2 \\
Micro Star Diamond Knives & A16 \\
MSA Call for Papers, Portland Meeting & A14 \\
SPI Supplies & A6, A15 \\
Ted Pella & A14 \\
XEI & 116 \\
\end{tabular}




\section{The \\ Power of}

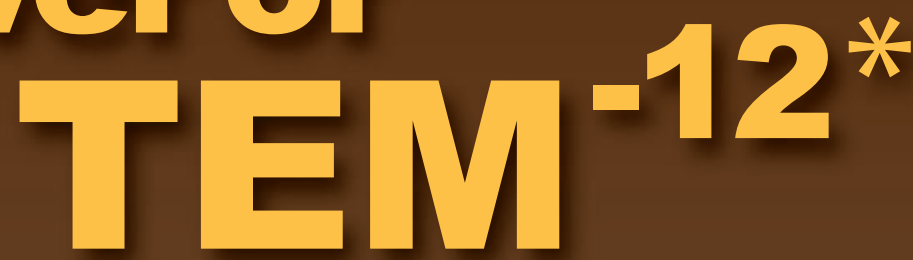

The best atomic level imaging and chemical mapping available today.

Seeing is believing. jeolusa.com/ARM200F

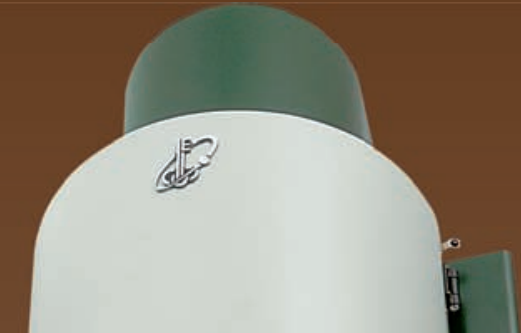

$\square$

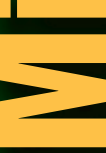

* 80 picometers, or 80 trillionths of a meter
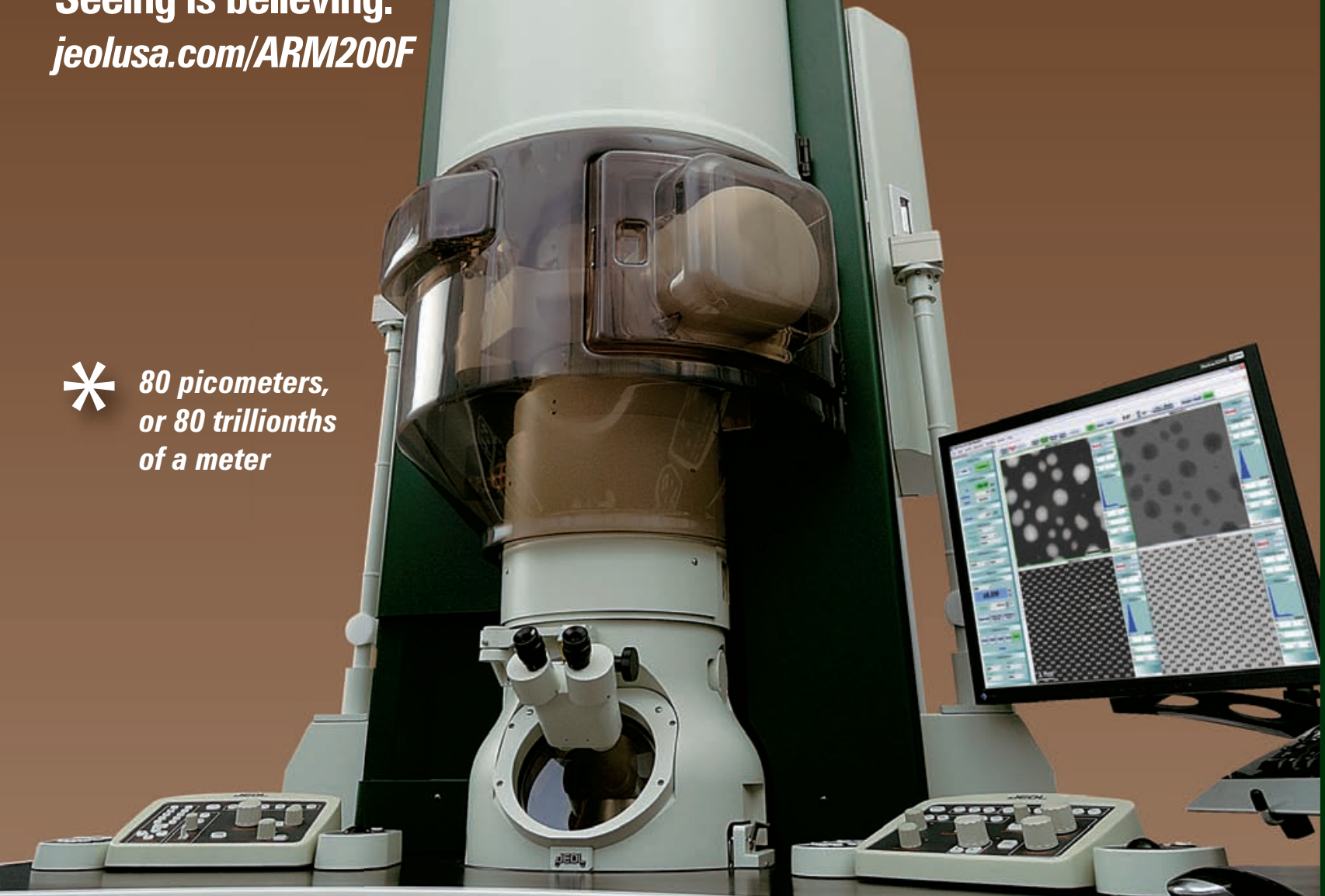